\title{
EMPLOYER BRANDING ON THE WEB: AN EMPIRICAL STUDY OF THE SELECTED POLISH COMPANIES

\author{
Kalina Grzesiuk ${ }^{1}$, Monika Wawer ${ }^{2}$
}

\begin{abstract}
This article concerns employer branding strategies implemented by the selected Polish companies. The main purpose of this paper is to present the current state of network tools utilization among the largest Polish private firms listed in 2017 by the Forbes Magazine. The media taken into consideration included the company's website career page and the firm's presence on the job related network sites such as: LinkedIn, GoldenLine, GoWork.pl and Pracuj.pl. The research described in this paper was based on a case study method. The results show that the company's website and the social network sites are effective tools for building a firm's profile as a part of employer branding strategies. However, with such a wide choice of the job related services available, a company must choose the services that allow the company to address the right target audience for active and passive job seekers.
\end{abstract}

JEL Classification Numbers: L14, M12, M51; DOI: http://dx.doi.org/10.12955/cbup.v6.1150

Keywords: employer branding, company's website, social media, human resources management

\section{Introduction}

The Internet has been used as a tool for recruitment for a number of years with the network being an important medium for spreading information about vacancies and seeking the right candidates (Ladkin $\&$ Buhalis, 2012). Due to the ICT development the recruitment process has become more cost effective, quick and based on reaching a wider range of prospective candidates. However, most recently it's the social network sites that are being increasingly used for effective recruitment.

With websites the majority of users are just consumers of content and in the networking sites the interactivity of the medium allows the users to co-create the content (Greaves, 2007). A company's website is usually built on a structure of pages with one main page and various cross-linked subpages. Whereas, social network sites are more similar to social network structures.

These two forms of a company's presence on the Internet were analysed for the purposes of this study. The analysis concerned the usage of the firm's website and the presence of the company on professional Social Network Sites (SNS) in the context of employer branding building strategies.

\section{Literature Review}

\section{The essence of employer branding}

According to Sathya \& Indradevi (2014) employer branding has become a strategic instrument for human resources (HR), helping employees to internalize a company values and organizational culture. From a human resources perspective, "employer branding, involves identifying the unique employment experience by considering the totality of tangible and intangible reward features that a particular organization offers to its employees" (Edwards, 2010, p.7). Born \& Kang (2015) identify the most important components that shape a strong employee brand. There are the following ones among them: assessment and shaping an authentic, consistent message of what your organization values, communicating the company's message by leveraging the right channels and developing employer branding metrics.

Employer branding represents what makes an organization attractive to its current and future employees (Mihalcea, 2017). The process of recruitment is of particular importance in this respect. Its proper implementation is related to the marketing guidelines called moments of truth (MOT) (Wilden, Gudergan \&Lings, 2010). These constitute moments that affect the candidates' assessment of the value of the company they apply for. The moments of truth verify their previous opinions and build lasting associations with a given company, and form future expectations of it. The analysis of each MOT stage in the candidate acquisition cycle allows one to identify areas in which positive relationships with the candidates can be created and maintained.

The moments of truth take place in the so-called touchpoints. These represent situations in which a prospective employee establishes a direct or indirect relationship with the company. Examples of touchpoints in the creation of the image of the employer are presented in Table 1. Each of the given

\footnotetext{
${ }^{1}$ Faculty of Social Sciences, John Paul II Catholic University of Lublin, Poland, kalina.grzesiuk@kul.pl

${ }^{2}$ Faculty of Social Sciences, John Paul II Catholic University of Lublin, Poland, monika.wawer@kul.pl
} 
moments of truth is an opportunity for the human resources departments to create a favourable or unfavourable impression and satisfy the expectations or dissatisfaction of the candidates.

\begin{tabular}{|l|l|}
\hline \multicolumn{1}{|c|}{ Table 1: Moments of Truth (MOT) and examples of Employer Brand Touchpoints } \\
\hline $\begin{array}{c}\text { Moments of Truth } \\
\text { (MOT) }\end{array}$ & \multicolumn{1}{c|}{ Examples of Employer Brand Touchpoints } \\
\hline Zero (ZMOT) & $\begin{array}{l}\text { Corporate and careers websites; social media; review sites; web search/online } \\
\text { research; digital advertising; }\end{array}$ \\
\hline First (FMOT) & $\begin{array}{l}\text { Word-of-mouth, referral conversations; job descriptions; recruiter/source } \\
\text { interactions; job application }\end{array}$ \\
\hline Second (SMOT) & Interviews; candidate communications; offer letter; hiring experience \\
\hline Third (TMOT) & On boarding; engagement \\
\hline Source: O'Brien (2017) \\
\hline
\end{tabular}

The Zero Moment of truth, in which the first relationship between the candidate and the company is created, is particularly important. It is crucial for the employer to be aware that this is a great opportunity to take action and to appear in the social media at the right place and time, and with the right message about the organization.

\section{Company website in employer branding}

A company's website is an important source of information for job seekers. Therefore, it could be used for attracting the most valuable job candidates. One of the advantages of using the company's website is that it is a company-dependent source of information and can be directly controlled to communicate a positive message to potential applicants (Hoye \& Lievens, 2007). Thus, firms have the freedom to create an appealing message in their own way. It also allows for the use of attractive content including powerful texts, images and audio/visual presentations (Young \& Foot, 2006).

Many organizations use their web pages for recruitment processes and the best tool for doing that is creating a career site. Using their own career website companies can post limitless job openings and reach a large number of candidates for a very low cost. Moreover, recruiting online saves time, as it enables firms to collect information about candidates more quickly. Usually such sites are not only supposed to reach the prospective employees but also convey a message about the firm's declared identity (Young \& Foot, 2006). Organizational recruitment websites often include information such as the company's mission and values, benefits and rewards, employees' testimonials and applied policies. Such information helps to build positive attitudes towards the organization (Intindola, Lewis, Flinchbaugh \& Rogers, 2017).The website is also an effective way to present the glorified image of work as one which allows the development of workers and offers substantial benefits (Young \& Foot, 2006). As Cober et al proved in their research (Cober, Brown \& Levy, 2004) the form, content and function of employment web sites have a strong influence on the job seekers decisions to apply.

\section{Recruitment related Social Network Sites in employer branding}

Company websites have been used for employer branding purposes for quite some time now and, as firms search for new ways to advertise to the prospective candidates, they start building their presence also on social networks sites. Employers are becoming increasingly aware of the benefits of using social media for HR decisions. As generation Y enters the labour market, the strategy of using online social networks for recruitment processes is becoming a standard procedure (Wilson, Gosling \& Graham, 2012). Younger users of SM are less concerned about their privacy and more willing to accept the idea of using the information available on their SM profiles by their potential employers (Peluchette $\&$ Karl, 2009).

One of the advantages of using social media in the context of employer branding is their interactivity. According to some previous studies the company controlled communication channels should be less credible for the stakeholders than media perceived as not company related, because they have a vital interest in publishing only the selected information presenting the company in a positive way (Kim \& Ferguson, 2014). However, in the case of social marketing sites the mechanism works in an opposite 
way. The information coming from the company itself is perceived as the most credible (Kissel \& Büttgen, 2015). The main reason for this counter intuitive phenomenon is that the SNS users think that the interactivity of social media gives them control over the information in the network, since users often base their opinion on the opinions, references and comments of others (Flanagin, Metzger, Pure, Markov \& Hartsell, 2014). It is simply not worthwhile for the company to risk publishing false information or hiding any negative facts because of the risk of unveiling and losing the firm's good image.

This is also one of the reasons why the use of social media by companies has downsides. It acts as a double-edged sword. The wide spread of information throughout the network applies to both the positive and negative features and behaviours of a company. That's why it is easy to destroy a firm's reputation through social media. The wide range of spreading the message about a job vacancy might also lead to some unintended consequences, as a company runs the risk of attracting a higher number of not qualified applicants (Sivertzen, Nilsen \& Olafsen, 2013).

Social media can also be an effective tool for building an employer's image through the involvement of employees (Morsing \& Schultz, 2006). Employees' main roles on social networking sites are giving opinions, seeking opinions and transmitting opinions. However, in order to benefit from their involvement, the firm needs to make sure they are aware of their role on social media and deal with the discontent of using their social media profiles in the professional setting (Cervellon \& Lirio, 2017).

\section{Data and Methodology}

The research described in this paper was based on a case study method. It involved the review of the social network sites used thus far by the 100 Largest Polish Private Companies listed in the 2017 Forbes Magazine report (Forbes 2017). The authors of the report have assumed that a Polish company is understood as a business entity in which the majority of shares belong to a Polish entrepreneur or a group of such people acting together. The group of such business entities also includes companies in which the entrepreneur has a minority share but actively manages or controls them through the supervisory board. A company's place in the list was determined by the company's market value (Enterprise Value, "EV") calculated according to current financial data available. In order to conduct an in-depth analysis, all companies included in the list were divided into three groups according to their value. The largest group consisted of 78 companies with EV up to 2000 million PLN (with average EV 1108 million PLN). The two other groups included 11 companies with EV between 2000 and 5000 million PLN (with average EV 3091 Million PLN) and 11 companies with EV above 5000 million PLN (with average EV 10241 million PLN).

There are many Social Network Sites available on the Internet and it is impossible to be present on all of them. Thus, every employer has to make a decision which of them would be the most effective for their branding and recruitment purposes. There are SNS that are more general and some that are professionally specific. Some of them are global and some local. For the purposes of this article one global and three local professional sites were analysed.

The main purpose of this paper is to present the current state of the website and SNS tools utilization among the largest Polish private firms. The media taken into consideration included the company's career webpage and the firm's presence on job related network sites such as: LinkedIn, GoldenLine, GoWork.pl and Pracuj.pl. In order to make sure the site was actively used by the company the authors had selected a time period of 28 days from February $1^{\text {st }}$ and February $28^{\text {th }} 2018$.

LinkedIn is the most frequently used global professional social network site for companies according to the 2016 SHRM Survey findings. It was indicated by $96 \%$ of the surveyed firms. Moreover, according to them, it was the most effective one for recruitment processes ("SHRM Survey Findings: Using Social Media for Talent Acquisition - recruitment and Screening," 2016). LinkedIn allows the employers, the employees and prospective job-seekers to create their own public profile. The users can also use search engines and build their networks of professional contacts.

The other portals analysed in this research are the most popular Polish job searching sites. GoldenLine is a portal offering recruitment and employer branding services. It provides job advertisements posting for candidates, reviews of employers and creating an individual professional profile. The functionalities include observing the employers perceived as interesting and posting opinions, comments and ranking the employer in relation to the salary, career opportunities, social benefits, people and atmosphere. For 
companies, the portal offers options to create recruitment ads and the candidate search engine. It also allows its users to create groups, exchange opinions and help each other through the users' forum.

GoWork.pl is another professional network site often used by job seekers and by the employers. The functionalities it offers include presenting a company's profile and advertising its job offers. It also enables users to post comments and opinions about the employer. They can also rate the company.

Pracuj.pl is one of the most popular job searching sites among job seekers in Poland. It allows companies to present their offers however, on this site prospective candidates can only see the job advertisements from the last 30 days. It's mostly used as a job board by the companies seeking candidates for their vacancies.

These three Polish sites differ in their popularity among job seekers. The statistics concerning their use are presented in Table 2 .

The main characteristics of the site's traffic include:

1. The number of visits monthly - an average of the number of visits each month in the last 6 months.

2. The bounce rate - the percentage of users that visit the website and leave it after seeing just one page.

3. Average visit duration - the average amount of time spent on the website by one user.

4. Pages per visit - the number of pages of the website seen during one visit of a particular user.

5. Percentage of e-recruiter destination sites - the percentage of users that follow the webpage to the e-recruitment tool at erecruiter.pl. It's a platform offering services related to e-recruitment, candidate experience management and building a network of collaboration with other partners in recruitment projects.

\begin{tabular}{|c|c|c|c|}
\hline $\begin{array}{ll}\text { Statistics } \\
\end{array}$ & GoldenLine & GoWork.pl & Pracuj.pl \\
\hline $\begin{array}{l}\text { Average total visits monthly in the last } 6 \text { months } \\
\text { (mln) }\end{array}$ & 6.13 & 5.12 & 15.41 \\
\hline Bounce rate & $69.66 \%$ & 68.64 & 33.51 \\
\hline Average visit duration (min:sec) & $1: 25$ & $2: 24$ & $5: 38$ \\
\hline Pages per visit & 2.04 & 1.78 & 5.95 \\
\hline Percentage of e-recruiter destination sites & $18.30 \%$ & $7.82 \%$ & $51.74 \%$ \\
\hline
\end{tabular}

The results of the comparison of the three portals show that the most popular site among job seekers is Pracuj.pl with 15.41 million of visits per month. GoldenLine and GoWork.pl are significantly less popular with 6.13 and 5.12 million users monthly, respectively. The bounce rate also shows that users are more engaged at Pracuj.pl and visit more than one page. The significantly longer average duration of one visit supports the notion of Pracuj.pl's higher popularity. Moreover, more than half of the users of this portal continued their visit at the e-recruitment site. The analysis of the results also shows that they are highly interconnected as the user of these portals were using them interchangeably.

\section{Results and Discussion}

\section{Company's Website}

Almost all of the selected firms have a company website. Only one of them during the time of analysis didn't have an active web page as it supposedly was under construction. Most of the companies (81\%) try to reach a diversity of potential candidates and make their webpage available in different language versions. Some of them also include options for people with visual disabilities (12\%). Companies use some media tools in order to make their website more interactive and publish newsletters (51\%), blogs (8\%) and have RSS channels (7\%).

The great majority (83\%) of all the companies of the Forbes list have a career page on their website. Although this site could theoretically serve various objectives, it is mostly used among these firms as a medium for posting job offers (93\%) and presenting information about the company (86\%). Some firms included also information about the benefits of the offered jobs (65\%), a description of the recruitment process $(55 \%)$ and the internship opportunities for the students (44\%). However, only about one quarter of company career pages included opinions of the employees (24\%). Based on these results companies were studied in relation to how many of the features were present on their websites. The functionalities 
considered included: job postings, information about the company, benefits of working for the company, description of the recruitment process, internship offers and employees' opinions.

The results of the analysis show that the contents of the companies' career pages are related to their size measured by the company value. The largest firms (with value above $5000 \mathrm{mln}$ PLN) have at least three of the enlisted elements with three being the dominant number (55\%). A significant percentage (37\%) of the smallest companies in the group, with value below $2000 \mathrm{mln}$ PLN, have none or just one of the elements enlisted above. The middle size firms (with value between 2000 and $5000 \mathrm{mln}$ PLN) have at least two of the elements, but most of them (54\%) have five or six elements. The detailed results of the ranking are shown in the Figure 1.

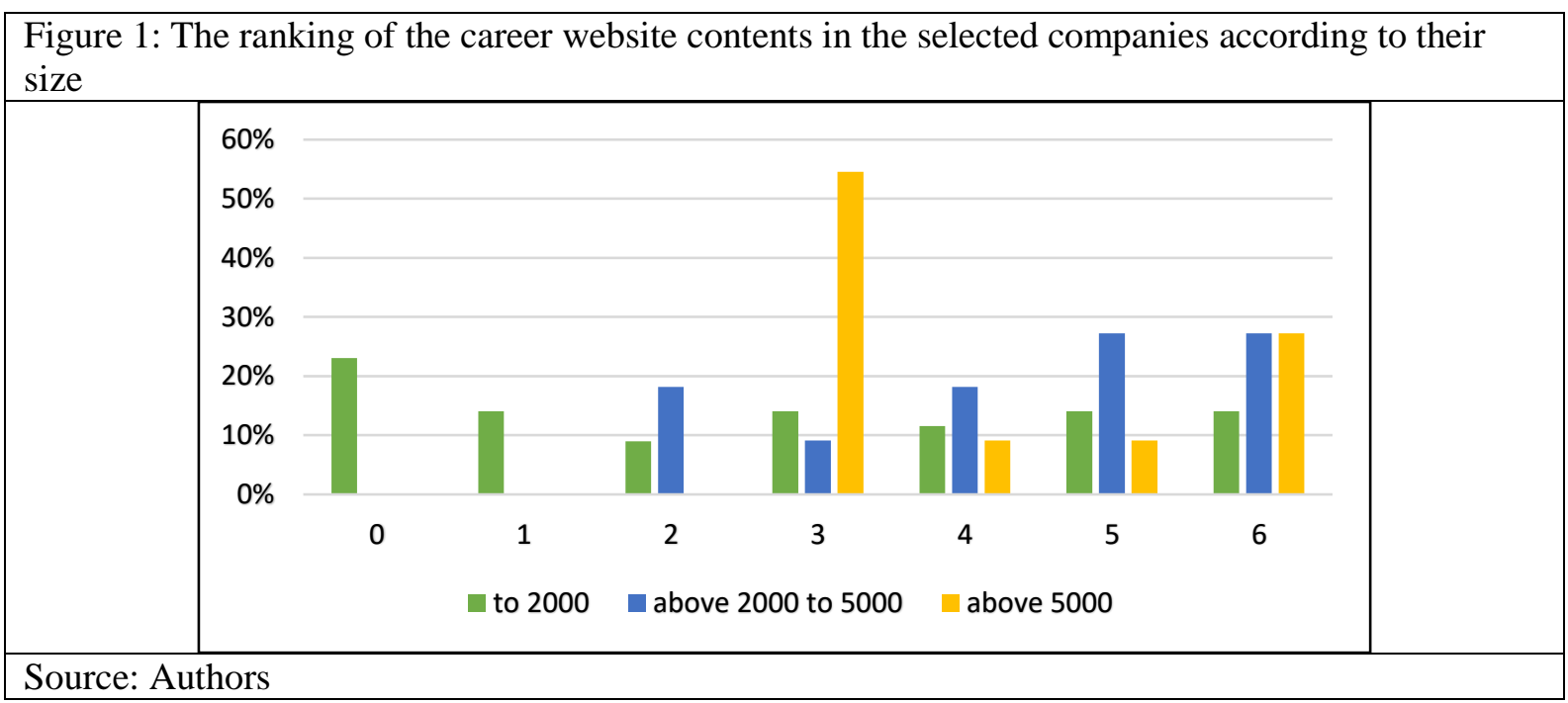

\section{LinkedIn}

LinkedIn is considered a global professional social network. Therefore it can be assumed that the largest and best companies are present there. However, the analysis of the activity of companies from the 100 Largest Polish Private Companies list indicates that during the analyzed period a large part of them was inactive on LinkedIn. No posts, likes or comments appeared in $69 \%$ of the smallest companies, $36 \%$ of medium and $45 \%$ of the largest ones. The indicators of activity on LinkedIn of analyzed companies depending on their size have been presented in Table 3.

Table 3: Activity indicators on LinkedIn of companies depending on their size

\begin{tabular}{|l|r|r|r|}
\hline \multicolumn{1}{|c|}{ Enterprise Value Range } & $\begin{array}{c}\text { Average number of } \\
\text { posts }\end{array}$ & $\begin{array}{c}\text { Average number of } \\
\text { likes }\end{array}$ & $\begin{array}{c}\text { Average number of } \\
\text { comments }\end{array}$ \\
\hline up to 2000 million PLN & 5.0 & 91.8 & 2.4 \\
\hline 2000 to 5000 million PLN & 2.4 & 56.4 & 5.1 \\
\hline above 5000 million PLN & 6.7 & 145.2 & 5.9 \\
\hline
\end{tabular}

Source: Authors

The analysis of the obtained results show that among the companies that were present on LinkedIn with the least activity were medium-sized companies. This is particularly evident in the area of average number of posts and likes (2.4 and 56.4), while with the largest companies these values are three times higher (6.7 and 145.2). Such results confirm their greatest commitment and effectiveness in building relationships with stakeholders and implementing employer branding strategies on the labour market. Also noteworthy are the high values of the two analyzed indicators for small companies (5.0 and 91.5). It can also be stated that LinkedIn is used to a much lesser extent by employees and prospective jobseekers to post their own comments.

\section{GoldenLine}

GoldenLine is used by employees, candidates, and directly by companies. The first group often assesses employers and adds their own opinions and comments. Employers most often publish job offers, and candidates use these two sources of information. The average rating for all companies issued by users 
of the portal is similar and ranges from 3.1 to 3.5. Also, the average number of opinions and average number of comments about companies of various sizes are almost the same (from 19.8 to 28.5). Detailed data has been presented in Table 4 .

Table 4: Activity indicators on GoldenLine of companies of different sizes

\begin{tabular}{|c|r|r|r|r|r|}
\hline $\begin{array}{c}\text { Enterprise } \\
\text { Value Range }\end{array}$ & $\begin{array}{c}\text { Average } \\
\text { rating of } \\
\text { employer }\end{array}$ & $\begin{array}{c}\text { Average number } \\
\text { of comments/ } \\
\text { opinions }\end{array}$ & $\begin{array}{c}\text { Number of } \\
\text { companies that } \\
\text { publish job } \\
\text { offers (activity) }\end{array}$ & $\begin{array}{c}\text { Average } \\
\text { number of job } \\
\text { offers per one } \\
\text { active company }\end{array}$ & $\begin{array}{c}\text { Average } \\
\text { number of } \\
\text { followers of } \\
\text { active company }\end{array}$ \\
\hline $\begin{array}{c}\text { up to 2000 } \\
\text { million PLN }\end{array}$ & 3.5 & 20.3 & 4 & 20 & 3996.3 \\
\hline $\begin{array}{c}\mathbf{2 0 0 0} \text { to 5000 } \\
\text { million PLN }\end{array}$ & 3.4 & 19.8 & 1 & 4 & 1672 \\
\hline $\begin{array}{c}\text { above 5000 } \\
\text { million PLN }\end{array}$ & 3.1 & 28.5 & 1 & 44 & 315 \\
\hline Source: Authors & & & & & \\
\hline
\end{tabular}

Source: Authors

It should be emphasized that in the analyzed period, i.e. from $1^{\text {st }}$ to $28^{\text {th }}$ of February 2018, only 6 out of 100 companies placed their job advertisements on the GoldenLine portal. This probably means that for employers this is not a priority source of recruitment for candidates. On the other hand, it is worth noting that the average number of followers is the largest for small companies $(3,996.3)$ and it is as much as ten times greater than for large companies. Perhaps this is related to the easier access to many different sources of information about large companies and the GoldenLine portal in this case is not needed and does not play a significant role.

\section{GoWork.pl}

GoWork.pl is another professional social network. $100 \%$ of large and medium-sized companies and $89 \%$ of small companies are presenting their company's profile and advertising job offers on this website. GoWork.pl is of particular importance to potential candidates in the recruitment process because it enables users to post their opinions about the employer. The main metrics of the companies that are present on GoWork.pl have been presented in Table 5.

\begin{tabular}{|l|r|r|r|}
\hline \multicolumn{1}{|c|}{ Table 5: Activity indicators on GoWork.pl of companies of different sizes } \\
\hline up to 2000 million PLN & $\begin{array}{c}\text { Average rating of } \\
\text { employer }\end{array}$ & $\begin{array}{c}\text { Average number of } \\
\text { ratings }\end{array}$ & $\begin{array}{c}\text { Average number of } \\
\text { comments/opinions }\end{array}$ \\
\hline 2000 to 5000 million PLN & 2.5 & 218.1 & 335.7 \\
\hline above 5000 million PLN & 2.7 & 256.6 & 447.5 \\
\hline
\end{tabular}

Source: Authors

Regardless of the enterprise value range, all companies received almost the same average ratings (2.5, $2.7,2.8$ ), with the greatest number of ratings being related to medium-sized companies (256.6), and the smallest one - to large companies (179.6). A similar tendency has been observed in case of the number of opinions placed on the profile by the users, with the number of opinions about mid-sized companies (447.5) being almost twice as large as the one about large companies (279.3). The obtained results allow to state that GoWork.pl is a portal thanks to which employer branding is most often carried out by medium-sized companies.

\section{Pracuj.pl}

Pracuj.pl is the most popular Polish portal dedicated primarily to publishing and searching for job offers. It is utilized by both employers and employees. The conducted research confirmed that in the analyzed time period, information on the need to fill the open positions was published by $72 \%$ of the surveyed large companies, $64 \%$ of medium-sized enterprises and $49 \%$ of small enterprises. There is a visible difference in the average number of job offers published by companies of all sizes, i.e. 31 for large companies, 17 for small ones and 9 offers for medium ones. The results of study have been presented in Table 6. 
Table 6: Average number of job offers published by active companies of different sizes on Pracuj.pl

\begin{tabular}{|c|c|c|}
\hline Enterprise Value Range & Percentage of active companies & Average number of job offers \\
\hline up to 2000 million PLN & $49 \%$ & 17 \\
\hline 2000 to 5000 million PLN & $64 \%$ & 9 \\
\hline above 5000 million PLN & $72 \%$ & 31 \\
\hline
\end{tabular}

Source: Autors

The analysis of obtained results allows one to state that companies with enterprise value range above 5000 million PLN, which are present on Pracuj.pl portal, are the most active in building relationships with candidates in the recruitment process.

\section{Discussion and Conclusions}

The study results show that, in the case of the largest Polish private companies, the company's website and social networking sites are tools often utilized for building a firm's profile as a part of employer branding strategies. Almost all of the selected firms have a company website. The contents of a companies' career pages are related to their size - the larger the company, the greater the variety of information available to potential users.

The analysis of the activity of companies from the 100 Largest Polish Private Companies list indicates that during the analyzed period a large part of them was inactive on the LinkedIn portal. The results also confirm that the largest companies with a value of over 5,000 million PLN are most engaged and most effective in building relationships with stakeholders and implementing the employer branding strategy through the presence on LinkedIn.

GoldenLine is a local portal. It is used by employers much less often and therefore is perceived as a less efficient source of candidates in the recruitment process. However, its superior value is the possibility for employees to express opinions or obtain information about the employer. Similar functions are performed by GoWork.pl, which is mostly used by medium-sized companies. A performed analysis allows one to conclude that in the contacts with candidates, through the publication of job offers, the Pracuj.pl portal is used to a significant extent. The large number of job offers of a given employer influences the growth of interest among various stakeholders and building a positive opinion about this company.

Summing up the results of the performed analysis, it should be stated that both the website and SNS strategies are very often implemented to ensure the effectiveness of candidate recruitment, and an important condition for the company's success in this area is the creation of a strong employer brand through the use of social networking sites. However, there is a limitation to the obtained results that should be pointed out. The analysis concerned only 100 of the most valuable private companies in Poland. It is possible that these dependencies are specific only for such organizations and would not appear in different contexts.

Based on the research results, certain managerial implications might be drawn. Firstly, the process of managing a company's presence on the internet in the context of employer branding requires making strategic decisions concerning the choice of tools that are the most effective in reaching prospective job candidates. Virtually all the stakeholders expect the company to be present on the internet and setting a website with a career page is the least a firm can do in order to create an employer brand on the labor market. However, there are some implications concerning the content of this page arising on the basis of the literature review and research results. Companies should be aware that it's really important to include not only standard, traditional elements of career page content, such as information about the company, job offers or a description of the recruitment process. The website should also provide opportunities to read or see employees' opinions about working for the company, but also stressing the benefits of working at the company, as a way of selling its values as an employer. It's also essential to implement tools that are rather rarely used, but really effective in allowing the webpage to be more interactive, such as disclosing a means of communication with the company and allowing the users to give feedback, comments or even co-create the website content.

The strategic decisions should also concern the presence of companies on social networking sites. As it is inviable to use all of them, a company should choose the ones that are the most effective in building their employer branding among the job seekers. The results of this research show that there are some 
key SNS a company should be present at, with LinkedIn being the most prominent one among them. One of the important aspects of their presence is creating a public profile. Most of the SNS allow voicing opinions about the companies and that's why firms have a very limited control over the information posted by other users about them. The profile page enables responding and dealing with negative publicity and presenting the company in a more favorable way. It's also essential that the message sent by a company throughout the social networking network, both by the website and the SNS, is characterized by integrity and consistency. Together with ensuring regular activity on the internet, it leads to creating the employer branding of a modern and dynamic company.

\section{References}

Born, N., \& Kil Kang, S. (2015). What are Best Practices in the Space of Employer Branding that Enable Organizations Attract and Retain the Best Talent?. Cornell University, ILR School. Retrieved from http://digitalcommons.ilr.cornell.edu/student/86.

Cervellon, M.-C., \& Lirio, P. (2017). When Employees Don't'Like'Their Employers on Social Media. MIT Sloan Management Review, 58(2), 63-70.

Cober, R. T., Brown, D. J., \& Levy, P. E. (2004). Form, content and function: An evaluative methodology for corporate employment WEB sites. Human Resource Management, 43(2-3), 201-218.

Edwards M.R., (2009) An integrative review of employer branding and OB theory, Personnel Review, Vol. 39(1), 5-23.

Flanagin, A. J., Metzger, M. J., Pure, R., Markov, A., \& Hartsell, E. (2014). Mitigating risk in ecommerce transactions: Perceptions of information credibility and the role of user-generated ratings in product quality and purchase intention. Electronic Commerce Research, 14(1), 1-23.

Forbes 2017. Największe polskie firmy prywatne 2017. Ranking "Forbesa", Retrieved from https://www.forbes.pl/rankingi/100-najwiekszych-firm-prywatnych-w-polsce-2017/twwjf75

Greaves, M. (2007). Semantic Web 2.0. IEEE Intelligent Systems, 22(2), 94-96.

Hoye, G. Van, \& Lievens, F. (2007). Investigating Web-Based Recruitment Sources- Employee testimonials vs word-ofmouse, International Journal of Selection and Assessment, 15(4), 372-382.

Intindola, M. L., Lewis, G., Flinchbaugh, C., \& Rogers, S. E. (2017). Web-based recruiting's impact on organizational image and familiarity: too much of a good thing?. International Journal of Human Resource Management, 5192, 1-22.

Kim, S., \& Ferguson, M. A. (2014). Public Expectations of CSR Communication: What and How to Communicate CSR. Public Relations Journal, 8(3), 1-22.

Kissel, P., \& Büttgen, M. (2015). Using social media to communicate employer brand identity: The impact on corporate image and employer attractiveness. Journal of Brand Management, 22(9), 755-777.

Ladkin, A., \& Buhalis, D. (2012). Online and social media recruitment: Hospitality employer and prospective employee considerations. International Journal of Contemporary Hospitality Management, 28(2), 153-160.

Mihalcea, A.D. (2017). Employer Branding and Talent Management in the Digital Age. Management Dynamics in the Knowledge Economy, 5 (2), 289-306; https://doi.org/10.25019/MDKE/5.2.07

Morsing, M., \& Schultz, M. (2006). Corporate social responsibility communication: stakeholder information, response and involvement strategies. Business Ethics: A European Review, 15(4), 323-338.

O'Brien, K. (2017). Moments that matter in the candidate experience, Exaqueo, February 21,

2017, http://www..com/blog/2017/2/moments-that-matter-in-the-candidate-experience

Peluchette, J., \& Karl, K. (2009). Examining Students’ Intended Image on Facebook: “What Were They Thinking?!” Journal of Education for Business, 85(1), 30-37.

Sathya, S., \& Indradevi, R. (2014). Branding for Talent Attraction and Retention of Employees: A Literature Review. International Journal of Scientific Research, 3(8), 202-204.

SHRM Survey Findings: Using Social Media for Talent Acquisition - recruitment and Screening. (2016). Retrieved from https://www.shrm.org/hr-today/trends-and-forecasting/research-and-surveys/Documents/SHRM-Social-Media-RecruitingScreening-2015.pdf

Sivertzen, A., Nilsen, E. R., \& Olafsen, A. H. (2013). Employer branding: employer attractiveness and the use of social media. Journal of Product \& Brand Management, 22(7), 473-483. https://doi.org/10.1108/JPBM-09-2013-0393

Wilden, R., Gudergan, S. \& Lings, I. (2010). Employer branding: strategic implications for staff recruitment, Journal of Marketing Management, 26(1-2), 56-73.

Wilson, R. E., Gosling, S. D., \& Graham, L. T. (2012). A Review of Facebook Research in the Social Sciences. Perspectives on Psychological Science, 7(3), 203-220.

Young, J., \& Foot, K. (2006). Corporate E-Cruiting: The Construction of Work in Fortune 500 Recruiting Web Sites. Journal of Computer-Mediated Communication, 11, 44-71. 